\title{
Ditadura, interesses empresariais e desenvolvimentismo: a obra da usina hidrelétrica de Tucuruí
}

\begin{abstract}
Resumo
O artigo pretende problematizar os interesses empresariais em torno do projeto da usina hidrelétrica de Tucuruí, construída durante a ditadura civil-militar brasileira. Indicando a falta de transparência na condução do projeto e do uso dos recursos públicos, analisamos a atuação dos diferentes beneficiários da obra, no que tange a aspectos como o financiamento, a realização da obra, a exploração da madeira da área inundada e o consumo da energia subsidiada por indústrias eletro-intensivas. Para proceder aos argumentos, acessamos fontes primárias produzidas por diversos agentes envolvidos no empreendimento. Concluímos que a usina de Tucuruí expressa em boa medida o perfil da ditadura brasileira, que, ao advogar por um discurso desenvolvimentista e nacionalista, escondia, por trás dele, interesses empresariais que se beneficiavam de seus projetos e do próprio caráter autoritário do regime, que garantia, dentre outras coisas, uma alta exploração da força de trabalho e elevadas margens de lucro às empresas.
\end{abstract}

Palavras-chave: Usina Hidrelétrica de Tucuruí. Grandes Barragens. Ditadura Civil-Militar Brasileira (1964-1988).

Empresariado. Desenvolvimentismo.

\author{
Pedro Henrique Pedreira Campos \\ Doutor em História pela Universidade Federal \\ Fluminense (UFF). Professor da Universidade \\ Federal Rural do Rio de Janeiro (UFRRJ). \\ Seropédica - RJ - BRASIL \\ phpcampos@yahoo.com.br \\ orcid.org/0000-0002-9280-3649
}

\section{Para citar este artigo:}

CAMPOS, Pedro Henrique Pedreira. Ditadura, interesses empresariais e desenvolvimentismo: a obra da usina hidrelétrica de Tucuruí. Tempo e Argumento, Florianópolis, v. 11, n. 26, p. 255 - 286, jan./abr. 2019.

\section{DOI: $10.5965 / 2175180311262019255$}

http://dx.doi.org/10.5965/2175180311262019255

\footnotetext{
1 Este artigo é fruto do projeto de pesquisa "As lutas dos atingidos pela usina hidrelétrica de Tucuruí - das primeiras mobilizações em contexto autoritário às condições de mobilização subsequentes à redemocratização do país", que conta com o apoio da Capes.
} 


\title{
Dictatorship, business
}

interests and

\section{developmentalism: the work of the Tucuruí hydroelectric power plant}

\begin{abstract}
The article intends to problematize the business interests around the Tucurui hydroelectric power plant project, built during the Brazilian civil-military dictatorship. Indicating the lack of transparency in the conduct of the project and the use of public resources, we analyze the performance of the different beneficiaries of the project, with regard to aspects such as financing, construction work, timber exploitation in the flooded area and energy consumption subsidized by electro-intensive industries. To proceed the arguments, we access primary sources produced by various agents involved in the enterprise. We conclude that the Tucurui power plant expresses in good measure the profile of the Brazilian dictatorship, which, by advocating for a developmentalist and nationalist discourse, hid behind it business interests that benefited from its projects and the authoritarian character of the regime itself, which guaranteed, among other things, a high exploitation of the workforce and elevated profit margins for companies.
\end{abstract}

Keywords: Tucuruí Hydroelectric Power Plant. Large Dams. Brazilian Civil-Military Dictatorship (1964-1988).

Entrepreneurship. Developmentalism. 
Só uma ditadura podia ter imposto à nação uma hidrelétrica como a de Tucuruí, no rio Tocantins. (PINTO, 2010, orelha do livro)

Este artigo propõe analisar os interesses empresariais envolvidos no projeto da usina hidrelétrica de Tucuruí, realizada pela Eletronorte, subsidiária da Eletrobrás, no rio Tocantins, entre 1975 e 1984, durante o período da ditadura civil-militar brasileira. Destacando a falta de transparência na condução do projeto e no uso dos recursos públicos - na elaboração do edital, na licitação, no contrato, nos seus aditivos e nos lucros das empresas envolvidas -, trabalhamos com a noção de Estado ampliado, desenvolvida na obra do autor marxista italiano Antonio Gramsci, para problematizar os interesses empresariais em jogo. Acessamos fontes primárias produzidas por diferentes agentes envolvidos no processo, como a estatal Eletronorte, as empreiteiras envolvidas na obra, além de pessoas que viveram no período e que denunciaram as polêmicas envolvidas no empreendimento, incluindo aí pesquisadores, parlamentares e jornalistas. Para o desenvolvimento do artigo, fizemos a divisão do mesmo em algumas partes. Em primeiro lugar, realizamos brevemente algumas reflexões teóricas importantes para se proceder à análise do caso. Em seguida, abordamos o projeto político do período, na forma do modelo de desenvolvimento implementado especificamente desde 1974. Inserido nesse programa, analisamos o caso da usina hidrelétrica de Tucuruí, explicando sua gênese histórica e implementação. Trabalhamos, em seguida, diferentes dimensões dos interesses envolvidos no projeto, incluindo alguns estrangeiros, associados ao financiamento parcial da obra e consumo da eletricidade produzida na usina, e os domésticos envolvidos com a construção do empreendimento e a exploração de madeira da área inundada. Em um tópico específico, abordamos a questão da alta exploração do trabalho durante a ditadura no Brasil, verificando como este se deu especificamente na construção da usina de Tucuruí. Concluímos desenvolvendo as interfaces entre o projeto problematizado e o regime político em vigor no país então, mostrando que a obra da usina de Tucuruí tem muito a revelar sobre o que foi e para quem foi a ditadura brasileira. 


\section{Breves reflexões teóricas}

As obras das grandes barragens no Brasil ao longo da ditadura suscitam uma série de indagações teóricas a respeito do melhor caminho para compreender o porquê da sua realização e também a forma como elas foram feitas. Dentre as diferentes possibilidades analíticas que a abordagem desse fenômeno permite, entendemos que é importante levar em consideração os interesses empresariais em torno desses projetos. Nesse sentido, as reflexões do pensador marxista italiano Antonio Gramsci parecem fornecer algumas premissas e fundamentos teóricos e metodológicos que parecem ser úteis para a compreensão do caso analisado. Ao criticar a separação liberal feita entre sociedade civil e sociedade política, Gramsci desenvolveu o que alguns consideram uma concepção ampliada de Estado, na qual a separação entre Estado e sociedade é basicamente metodológica, e não orgânica (GRAMSCl, 2000).

Essa teorização parece ser aplicável para o caso analisado, visto que supera a separação jusnaturalista entre Estado e sociedade e permite compreender como as classes sociais e suas frações se relacionam não apenas na sociedade civil, mas também no interior da sociedade política, isto é, dentro do Estado restrito. Dessa forma, podemos perceber os diferentes interesses envolvidos naquele processo em conjugação e disputa no interior do aparelho de Estado. Assim, parece esclarecedora a apreensão feita por Sonia Regina de Mendonça² acerca dos escritos e reflexões de Gramsci:

Pensar o Estado gramscianamente é pensá-lo sob dupla perspectiva: 1) a das formas mediante as quais as frações de classe se consolidam e organizam para além da produção, no seio da Sociedade Civil e 2) a das formas através das quais as agências ou órgãos públicos contemplam projetos e/ou atores sociais emanados dos aparelhos privados de hegemonia dos quais a Sociedade Civil é portadora. (MENDONÇA, 2007, p. 15, grifo da autora)

\footnotetext{
${ }^{2}$ Mesmo sendo uma importante pesquisadora que se baseia na obra de Gramsci, Sonia Mendonça, por certo, não é a única autora brasileira que se arvora na obra do autor italiano. Pelo contrário, os escritos de Gramsci deram origem a diversas interpretações e aplicações entre os especialistas brasileiros. Para alguns outros, ver: BIANCHI, Alvaro. O Laboratório de Gramsci: filosofia, história e política. São Paulo: Alameda, 2008 ; COUTINHO, Carlos Nelson. Gramsci: um estudo sobre seu pensamento político. 2. ed. amp. Rio de Janeiro: Civilização Brasileira, 2003 ; ROIO, Marcos del. Os prismas de Gramsci: a fórmula política da frente única (1919-1929). São Paulo: Xamã, 2005 , dentre outros.
} 
Assim, adotando a noção gramsciana de Estado ampliado, é fundamental entender como as frações de classe se organizam e desenvolvem projetos no âmbito da sociedade civil; e como as políticas estatais complementam esses agentes sociais devidamente organizados em aparelhos privados de hegemonia.

No caso da obra de Tucuruí, pretendemos verificar quais são os interesses em torno da política energética brasileira no período, como eles estão organizados e quais foram os grupos contemplados pelas ações e políticas desenvolvidas pelas agências estatais no setor.

Antes de abordar os agentes e as políticas implementadas pela ditadura para o setor energético, precisamos problematizar o regime político no qual estas foram postas em prática. René Armand Dreifuss estudou em sua tese de doutorado o golpe de Estado de 1964 no Brasil e analisou a participação do Instituto de Pesquisas e Estudos Sociais (o Ipes) nesse processo. O Ipes reunia empresários, sobretudo ligados ao capital internacional e associado a empresas estrangeiras, além de oficiais militares ligados à Escola Superior de Guerra (ESG), articulados com órgãos do governo norte-americano. Assim, Dreifuss interpretou a ditadura brasileira:

O novo Estado estabelecido em 1964 agiu, não só em nome do bloco de poder financeiro-industrial multinacional, mas também sob o comando do bloco de poder vigente organizado no IPES. O Estado de 1964 era de fato um Estado classista e, acima de tudo, governado por um bloco de poder. (DREIFUSS, 1981, p. 488)

Desse modo, Dreifuss demonstra em sua seminal pesquisa como os interesses do capital internacional e associado, organizados no âmbito do Ipes e em outros aparelhos privados de hegemonia, tiveram papel fundamental na derrubada da democracia no país em 1964 e tomaram as rédeas do aparelho de Estado brasileiro já a partir do governo Castello Branco (1964-1967).

No entanto, em meio ao processo de desenvolvimento dos mais de 20 anos de ditadura civil-militar no Brasil, os interesses do capital internacional e associado foram altamente contemplados pelas políticas estatais - no caso do projeto de Tucuruí, sobretudo capitais japoneses -, mas o foram também alguns empresários de capital predominantemente doméstico, mediante uma política de proteção seletiva das 
companhias e que correspondia aos próprios interesses e projetos de alguns agentes da classe dominante brasileira, devidamente organizados na sociedade civil. Assim, conforme pontuaram Maria Moraes e Guido Mantega, em 1980:

Nestas últimas duas décadas, as taxas de crescimento da produção foram de causar inveja até mesmo aos admiradores do "milagre" japonês, enquanto o país se transformava num verdadeiro paraíso para o capital estrangeiro. Mas não foram apenas as colossais empresas americanas e alemãs que configuraram a "nova potência emergente" do Continente Americano. Ao lado e à sombra dos monopólios estrangeiros forjaram-se grupos monopolistas nacionais que, amplamente escorados na generosidade do Estado, desempenham um papel importante na conformação do capitalismo brasileiro. (MORAES; MANTEGA, 1980, p. 8384 , grifo nosso).

Logo, os autores apontam para o processo de crescimento e amadurecimento de alguns grupos de capital brasileiro ao longo da ditadura. Essas empresas passaram a ter um novo porte, presença em boa parte do território nacional e alguns chegaram a já, desde aquele período, desenvolver atividades no exterior. Dessa forma, a mesma ditadura que favoreceu o capital multinacional estrangeiro, defendeu e apoiou a formação do capital monopolista doméstico. Como veremos adiante, essas ponderações parecem ser importantes para se entender certos aspectos e características da obra e dos beneficiários do projeto de Tucuruí.

\section{O projeto de desenvolvimento da ditadura e o caso do II PND}

O longo período de mais de vinte anos da ditadura civil-militar brasileira não abriga políticas estatais de mesmo tipo. As variações se explicam por diferentes motivos. Em primeiro lugar, dentro do grupo golpista de 1964, havia diferentes segmentos com interesses e projetos distintos, fazendo com que algumas sucessões no interior da ditadura representassem modificações nas políticas estatais implementadas. Além disso, as diversas conjunturas internacionais encontradas nos anos 1960, 1970 e 1980 levaram a reorientações de programas, conforme a conveniência e as possibilidades de cada momento. 
Dessa forma, o governo, inaugurado em março de 1974, estava condicionado diretamente pelo choque internacional do ano anterior, quando houve a elevação substantiva do preço do petróleo - e de vários outros produtos no mercado internacional, como matérias-primas e bens de produção - e o início de uma longa crise da economia capitalista mundial. Houve uma elevação dos juros praticados internacionalmente e a economia brasileira foi especialmente afetada pelo choque no setor energético, tendo em vista que, no início da década de 1970 , cerca de $80 \%$ do petróleo consumido no Brasil era importado. Assim, a balança comercial brasileira, que gozava de razoável equilíbrio na passagem dos anos 1960 para os anos 1970, passou para um profundo déficit (GASPARI, 2003; CAMPOS, 2014).

O abalo internacional de 1973 pôs em xeque o modelo do desenvolvimento do chamado "milagre" econômico. Esse correspondeu a um período de elevado crescimento da economia brasileira entre os anos de 1968 e 1973, com cifras anuais superiores aos dois dígitos. A explicação para as altas taxas de expansão da atividade produtiva residiam no financiamento externo, via investimentos ou via empréstimos, e na distribuição disciplinada da renda nacional, com contenção dos ganhos salariais e repressão aos movimentos de trabalhadores pelo regime. Assim, houve crescimento no compasso da própria concentração de renda na sociedade brasileira e da elevação da dependência externa da economia. Com o choque internacional do petróleo, houve o fim da liquidez internacional de crédito e investimentos, esgotando-se o modelo do "milagre" (SINGER, 1978; PRADO; EARP, 2003).

O governo Geisel montou um novo modelo de desenvolvimento para substituir o padrão em vigor anteriormente, porém também de perfil autoritário. O projeto do governo previa a execução do plano em meio ao processo de transição política para o regime democrático. Um dos seus itens fundamentais é que a abertura ocorresse em um ambiente de crescimento econômico. Para manter as altas taxas de acumulação, o Estado substituiria o capital estrangeiro como principal financiador dos investimentos (OLIVEIRA, 1977; MENDONÇA, 1985). Além disso, como resposta à elevação do valor das importações, foi montado um grande programa de substituição de importações, como indicam Pedro Cezar Dutra Fonseca e Sergio Marley Modesto Monteiro: 
Desde que veio a público, em setembro de 1974, seis meses após a posse do presidente Ernesto Geisel, e ao longo de sua execução, o II Plano Nacional de Desenvolvimento (II PND) foi objeto de acaloradas polêmicas. Sua proposta central de imprimir novo rumo ao desenvolvimento brasileiro, ao priorizar o aumento da capacidade energética e da produção de insumos básicos e de bens de capital, representava uma guinada de vulto no modelo anterior, vigente durante o período do "milagre" de 1968-1973, cuja prioridade residia nos bens de consumo duráveis. Parecia extemporâneo e fora de propósito acelerar a economia a partir de megaprojetos, sob a forte liderança estatal, justamente quando vários países ajustavam-se, através da recessão, à nova realidade advinda da quadruplicação do preço do petróleo. Ademais, a opção por acelerar o processo de substituição de importações, explicitada no plano, em boa medida lembrava as teses cepalinas, combatidas pelos principais economistas do regime militar. (FONSECA; MONTEIRO, 2007, p. 28-29)

Como apontam os autores, o II PND constituía um programa para fazer frente ao choque internacional de 1973, substituindo as importações de produtos que voltaram a ser importados durante o período do "milagre", como produtos siderúrgicos (metais não ferrosos), papel e celulose, químicos, petroquímicos e fertilizantes (OLIVEIRA, 2003; CASTRO; SOUZA, 1985).

Dessa maneira, foram montadas iniciativas, em geral de grande porte, para atender às metas estipuladas no plano. Foram projetadas novas plantas siderúrgicas - em Itaqui (Maranhão), Tubarão (Espírito Santo), Açominas e Siderúrgica Mendes Júnior (ambas em Minas Gerais) -, foi montado um grande programa para explorar o petróleo descoberto na bacia de Campos, planejados oleodutos, polos petroquímicos, programa de telecomunicações e investimentos na área de energia. No que tange à eletricidade, foram formulados e reforçados projetos alternativos aos combustíveis fósseis. Assim, foram elaboradas propostas de plantas de usinas termonucleares, com o acordo BrasilAlemanha; foi criado o Programa Pró-Álcool, de estudos e incentivo ao uso de álcool combustível em automóveis; e foram iniciadas e aceleradas obras de usinas hidrelétricas. Para fazer frente ao déficit comercial externo, foram tomadas também algumas medidas para reduzir as importações, como a proibição de compra externa de automóveis e de microcomputadores (CAMPOS, 2014). 
Inserido na "estratégia de 74" estava um projeto autoritário de Brasil potência, com investimentos em pesquisa e tecnologia de ponta, nos nichos da assim chamada "Terceira Revolução Industrial". Por conta disso, foram desenvolvidos programas nas áreas bélica, de telecomunicações, de informática, nuclear, de química fina e em outros setores industriais de intensa tecnologia. A política de transportes também foi remodelada, sendo abandonada a prioridade antes reservada aos projetos rodoviários. Desse modo, iniciativas no setor hidroviário e ferroviário - como a Ferrovia do Aço e o trem-bala Rio-São Paulo -, foram formuladas, apesar de não terem sido concluídas ou mesmo iniciadas no período (LESSA, 1988; SILVA, 2000; CAMPOS, 2014).

Com o propósito fundamental de substituir importações e ampliar as vendas internacionais, foram montados grandes projetos na região amazônica. Coadunado com o perfil do II PND, assim foi explicada a opção pela usina hidrelétrica de Tucuruí pelo ditador Ernesto Geisel:

Outra grande usina hidrelétrica que construímos foi Tucuruí, no Pará, com o objetivo, além de suprir aquela região, principalmente Belém, de aproveitar a bauxita de Oriximiná, às margens do Trombetas, para a produção de alumínio em grande escala. Nós tínhamos produção de bauxita, mas importávamos quase todo o alumínio que consumíamos. Tínhamos uma pequena indústria de alumínio em Minas Gerais e a Votorantim, em São Paulo. E no entanto o alumínio é um material essencial para muitas indústrias. Então, procuramos desenvolver a produção de alumínio no Norte, no Pará e no Maranhão. Mas não havia energia elétrica, que é o principal insumo da produção de alumínio, e por isso resolvemos fazer Tucuruí. Presentemente o Brasil é um grande produtor de alumínio, no Maranhão e no Pará, graças a essa grande usina. São Luís do Maranhão também é suprida por Tucuruí. Há poucos anos, quando o nível do rio São Francisco baixou, por causa da estiagem nas cabeceiras, e Paulo Afonso não pôde fornecer toda a energia consumida no Nordeste, Tucuruí forneceu, através de uma linha de transmissão até Sobradinho, o complemento de energia para suportar o déficit. Outras usinas em várias regiões do país foram iniciadas ou concluídas. Os gastos correspondentes foram avultados, mas certamente compensados. (D'ARAÚJO; CASTRO, 1997, p. 303)

Por essa razão, a barragem de Tucuruí foi formulada em boa medida de forma subsumida ao modelo de desenvolvimento implementado a partir de 1974, com um projeto voltado para a substituição de importações e em resposta ao choque internacional de 1973. Vejamos mais detalhes sobre o empreendimento. 


\section{A usina hidrelétrica de Tucuruí}

A ditadura brasileira desenvolveu diversos e impactantes projetos na Amazônia. Atendendo às orientações geopolíticas do pensamento militar, que defendia a integração daquela região do território - o que vinha atrelado a interesses empresariais -, a região sofreu uma série de incursões no período, no sentido de incorporá-la à economia capitalista brasileira e internacional. Foram muitos os projetos de grande envergadura para a região durante o regime, como as rodovias Transamazônica, Cuiabá-Santarém e Perimetral Norte; a zona franca de Manaus; diversas iniciativas agropecuárias, extrativistas e minerais, como o projeto grande Carajás; e as usinas hidrelétricas de Samuel (no rio Jamari, em Rondônia), Balbina (no rio Uatumã, no Amazonas) e Tucuruí (no rio Tocantins, no Pará). No caso desses projetos, a justificativa geopolítica e militar de ocupação do território - prevista em lemas do regime, como o "Integrar para não entregar" (OLIVEIRA, 1991) -, sob uma pretensa orientação nacionalista, servia para encobrir interesses econômicos capitalistas que se beneficiariam intensamente daquelas iniciativas.

De todos esses projetos, o de maior envergadura foi o da usina hidrelétrica de Tucuruí. Situada no rio Tocantins, no Pará, a 310 quilômetros de Belém, a obra da usina foi iniciada no ano de 1975 e concluída em 1984. Com seus 8.370 megawatts (MW) de potência instalada final atingidos em 2006, trata-se da maior hidrelétrica plenamente brasileira - a usina de Itaipu é binacional brasileiro-paraguaia - e a quarta maior do mundo hoje. A obra teve seus custos redimensionados diversas vezes ao longo dos trabalhos, saindo de um valor inicial de US\$ 2,1 bilhões e chegando a US\$ 5 bilhões (CENTRAIS ELÉTRICAS DO NORTE DO BRASIL S/A, 1989), segundo os dados oficiais, ou US\$7,5 bilhões de acordo com a Comissão Mundial de Barragens, e até US\$ 10 bilhões, segundo alguns críticos do empreendimento (PINTO, 2010).

A obra foi conduzida pela Eletronorte, subsidiária da Eletrobrás, criada em 1973, e formada prioritariamente para conduzir o projeto de Tucuruí. A Eletronorte sucedeu ao Eneram (Comitê Coordenador de Estudos Energéticos da Amazônia), organismo criado em 1968, pelo Ministério de Minas e Energia para fazer o inventário com o potencial dos rios da região Norte do país (CENTRAIS ELÉTRICAS DO NORTE DO BRASIL S/A, 2004). 
Porém, desde o seu início, a obra não remonta apenas a um suposto planejamento racional estatal, mas também à satisfação de certos interesses capitalistas específicos. Empresários japoneses e brasileiros levaram ao governo a proposta de construir uma usina hidrelétrica na região de modo a beneficiar a bauxita encontrada em grandes proporções nas margens do rio Trombetas. A produção de alumínio e alumina a partir da bauxita é uma das atividades industriais que mais demanda consumo de energia elétrica, insumo que por sua vez constitui um dos principais componentes do custo da produção do metal, cujo consumo estava em franca expansão no mercado mundial na década de 1970 (PINTO, 2010; O EMPREITEIRO, 1981).

Os japoneses estavam redimensionando a sua economia e o seu parque industrial após o choque internacional do petróleo de 1973. Sem contar com reservas de petróleo ou outras fontes de energia elétrica de grande monta em seu território, o país estava deslocando para outros territórios suas plantas fabris de alumínio. Para isso, viram uma grande oportunidade no Brasil, com a descoberta de bauxita no Pará, e em outros países - como Indonésia e Austrália. A proposta era que os japoneses atuassem - com financiamento, tecnologia e participação nos negócios - nas minas de exploração, nas ferrovias de transporte, na usina hidrelétrica e, principalmente, nas fábricas de produção de alumínio situadas perto de Belém e de São Luís. Com isso, eles poderiam desativar as indústrias em seu território, exportando as plantas fabris eletrointensivas para regiões com grande capacidade de produção de energia elétrica, como a Amazônia brasileira. Toda a negociação teve a participação da Vale do Rio Doce, que entrou como sócia do negócio, e do empresário Eliezer Batista, ex-presidente da Vale e antigo ministro de Minas e Energia do governo Goulart, e que tinha sido afastado de suas funções públicas desde o golpe de 1964, retomando a presidência da estatal brasileira de mineração no governo Figueiredo (PINTO, 2010; BATISTA, 2009).

O projeto de exploração e beneficiamento das jazidas de bauxita não constituíra o único programa mineral da Amazônia no período. Na região Sul do estado do Pará foram encontradas grandes reservas minerais que deram origem ao projeto Grande Carajás, com exploração, beneficiamento e exportação de minério de ferro, ouro, manganês, níquel, estanho e cobre. Para dar vazão à exploração desses produtos, foi feita uma 
grande ferrovia, a estrada de ferro Carajás, e no projeto seria consumida a energia gerada pela usina de Tucuruí (O EMPREITEIRO, 1980B)3.

A obra de Tucuruí começou em 1975, com os serviços iniciais e o desvio do rio. Apesar da prioridade dada à obra pelo regime, ela sofreu seguidos atrasos e só foi concluída em sua primeira etapa no ano de 1984. Com a instalação paulatina das turbinas e dos geradores, ela iniciou com capacidade instalada de $660 \mathrm{MW}$, com apenas duas máquinas funcionando. Após a instalação de todos os equipamentos ao longo da década de 1980, ela chegou à capacidade máxima da primeira etapa, de $4000 \mathrm{MW}$. Nos anos 1990, houve a ampliação da usina e, com isso, ela dobrou a sua potência, chegando à capacidade máxima de mais de $8000 \mathrm{MW}$ na primeira década do século XXI, quando foi instalada a sua última turbina (CENTRAIS ELÉTRICAS DO NORTE DO BRASIL S/A, 2004).

Além de abastecer a exploração dos projetos minerais da Amazônia, as fábricas de alumínio de Belém e São Luís, a usina supriria de energia elétrica o estado do Pará, além de ter ligação com outras subsidiárias da Eletrobrás. Assim, foi feita uma conexão com o sistema da Chesf (Companhia Hidrelétrica do Vale do São Francisco, responsável pela geração e transmissão de energia na região Nordeste) e Tucuruí acabou atuando parcialmente para fornecer eletricidade às cidades e regiões nordestinas. A proposta do governo é que houvesse uma complementaridade entre o sistema Chesf e o Eletronorte, tendo em vista que o pique de chuvas na região amazônica ocorre nos meses de março e abril e, o do Nordeste, nos meses de maio a julho. Depois, na década de 1990, foi feita a conexão por linhas de transmissão da energia gerada por Tucuruí com o Centro-Sul (CENTRAIS ELÉTRICAS DO NORTE DO BRASIL S/A, 2004).

Apesar do discurso oficial favorável, a obra esbarrou em uma série de polêmicas. A hidrelétrica formou, em plena região amazônica, o segundo maior lago artificial do país, com um total de $2.600 \mathrm{~km}^{2}$, só menor que o de Sobradinho, na Bahia. Foram aproximadamente 23 mil pessoas deslocadas em função da obra, por estarem no interior da área onde se criou o reservatório, além dos impactos ambientais negativos para a numerosa população ribeirinha do baixo Tocantins, situada à jusante da barragem

\footnotetext{
3 Sobre a ferrovia de Carajás, ver, dentre outros, COELHO, Maria Célia Nunes. A ocupação da Amazônia e a presença militar. São Paulo: Atual, 1998.
} 
(ACSELRAD, 1991; SANTOS, 2007). Houve também uma série de polêmicas ambientais, trazidas no relatório de Robert Goodland e em estudos desenvolvidos por pesquisadores e jornalistas da região. O impacto ambiental, então em debate, se referia à possível salinização do rio Tocantins, destruição de fauna e flora com a criação do reservatório, dentre outras consequências danosas ${ }^{4}$.

No entanto, vamos nos deter aqui em quatro questões específicas referentes à usina de Tucuruí, privilegiando os interesses em torno do projeto e que, de acordo com nossa argumentação, têm algo a revelar acerca da própria ditadura brasileira. Assim, trabalharemos os interesses militares no projeto, os interesses estrangeiros - referentes ao financiamento da obra, fornecimento de equipamentos para a usina e consumo da energia produzida -, os interesses domésticos - relacionados principalmente às empreiteiras responsáveis por sua obra - e o tratamento dispensado à força de trabalho ao longo da construção da usina. Como veremos, essas não são questões separadas entre si, mas que se entrecruzam e figuram na realidade de forma combinada e complexa. Faremos a separação apenas como mecanismo metodológico para melhor análise e compreensão da questão.

\section{Os interesses militares em torno de Tucuruí}

Uma das principais atividades da cidade de Tucuruí antes da obra da usina era a exploração de madeira da região, o que competia como principal atividade econômica local, ao lado da extração de castanha e exploração de ouro e diamante. Com a proposta da usina e a projeção da área inundada, abriu-se uma grande oportunidade na região, que foi a possibilidade de exploração prévia da madeira das árvores da área que seria coberta pelo lago artificial. Os militares se interessaram pelo tema e o Serviço Nacional de Informações (SNI), órgão de espionagem da ditadura, acabou se apropriando do projeto

\footnotetext{
${ }^{4}$ Não vamos aprofundar neste artigo as questões sócio-ambientais referentes ao projeto de Tucuruí. Para isso, ver: SANTOS, Sônia Maria Simões Barbosa. Lamento e dor: uma análise sócio-antropológica do deslocamento compulsório provocado pela construção de barragens. Tese (Doutorado em Ciências Sociais) - UFPA, Belém, 2007. ; ROCHA, Gilberto de Miranda. Todos convergem para o lago: hidrelétrica de Tucuruí, municípios e territórios da Amazônia. Belém: UFPA, 2008. ; PINTO, Lúcio Flávio. Tucuruí: a barragem da ditadura. Belém: Edição do autor, 2010. Para o caso de Sobradinho, ver: COSTA, Ana Luiza Martins. Uma retirada insólita: Rio São Francisco, barragem de Sobradinho. Rio de Janeiro: UFRJ, 2013.
} 
(GASPARI, 2002). Formalmente, o Instituto Brasileiro de Desenvolvimento Florestal (IBDF) foi incumbido pelo governo federal de conduzir a questão e o órgão contratou, em 1975, a Capemi Agropecuária para explorar a madeira local. A empresa constituía propriedade da Caixa de Aposentadoria dos Militares (Capemi), fundo de previdência criado em 1960 e controlado pela cúpula militar (CAPEMI, 2016).

O projeto era de grande monta e poderia representar uma atividade econômica bastante rentável, tendo em vista que a Capemi acabou responsabilizada por explorar uma área de 11 mil hectares de árvores de grande porte e com madeira de alta qualidade e elevado valor no mercado internacional. Só algumas árvores locais tinham troncos de 20 toneladas, com amplas possibilidades econômicas. A empresa contraiu um empréstimo internacional junto ao Banco Nacional de Paris e chegou a atuar em algumas áreas previstas, explorando troncos, instalando unidades fabris no local, usando máquinas, fazendo madeiras laminadas e vendendo para o mercado doméstico e internacional (CAPEMI, 2016; ASSIS, 2015).

No entanto, a Capemi Agropecuária, que não possuía habilidade técnica ou experiência no assunto que justificasse a sua contratação, foi acusada de usar produtos químicos desfolhantes na floresta e se envolveu com uma série de operações suspeitas. A empresa acabou falindo, desmatando apenas $10 \%$ da área prevista no contrato. Com isso, a madeira local não foi explorada plenamente na ocasião e o lago foi formado em uma grande área com matéria orgânica, levando ao fenômeno da eutrofização, com liberação de dióxido de carbono e metano na atmosfera devido à decomposição do material orgânico inundado. A manutenção das árvores na região inundada pelo lago artificial constituiu também um problema para o funcionamento posterior da usina, visto que os resíduos da vegetação atrapalhavam a operação das turbinas (PINTO, 2010; ASSIS, 2015; GASPARI, 2002).

Apesar de ter sido um fiasco, o caso do envolvimento da Capemi com a exploração de madeira da área alagada de Tucuruí indica o interesse e o envolvimento dos militares com projetos tocados ao longo da ditadura. Longe de apenas viabilizar projetos empresariais de grupos internacionais e domésticos, segmentos das forças armadas desempenharam um papel de sócios de alguns desses empreendimentos, o que é 
indicativo da posição desempenhada por alguns setores da corporação militar nos grandes projetos econômicos do regime5.

\section{Os interesses empresariais internacionais em torno de Tucuruí}

Diversos interesses empresariais estrangeiros estiveram envolvidos com o projeto da hidrelétrica de Tucuruí. Estes estavam associados à exploração, beneficiamento e exportação dos minerais e seus derivados, ao consumo da energia elétrica gerada pela usina e também ao financiamento e provimento de equipamentos para o funcionamento de Tucuruí. Em torno disso, estiveram presentes empresas mineradoras, industriais e bancárias do Japão, França, Estados Unidos, Canadá, Alemanha e, mais recentemente, Noruega.

Para cada fase do projeto mineral-industrial foram criadas empresas na forma de joint-venture envolvendo a então estatal brasileira de mineração e empresas estrangeiras. Assim, para a exploração da bauxita na região de Oriximiná, ao largo do rio Trombetas, foi formada a Mineração Rio do Norte, que tinha participação de $46 \%$ da Companhia Vale do Rio Doce (CVRD), 10\% da Companhia Brasileira de Alumínio (CBA, do grupo Votorantim), $19 \%$ da Alcan, $5 \%$ da Reynolds e o resto de outras firmas estrangeiras. A bauxita era explorada ali e seguia por ferrovia e rios para a grande Belém e São Luís, onde seria beneficiada em fábricas de alumínio que foram construídas para o projeto ( $\mathrm{O}$ EMPREITEIRO, 1981).

Estas eram algumas das maiores indústrias de alumínio do mundo. A maior delas, a Albrás, ficava no município de Barcarena, perto de Belém, e tinha capital majoritário da Vale (51\%) e, o resto, da japonesa Valenorte Amazon Aluminiun, ou Nalco, que reunia 32 empresas japonesas do setor de alumínio e tinha $49 \%$ do projeto. Só essa fábrica tinha previsão de US\$ 1,34 bilhão de investimentos. Com o desenvolvimento do projeto, a fábrica foi redimensionada e reduzida de tamanho. Após a privatização da Vale, a

\footnotetext{
${ }^{5} \mathrm{O}$ caso Capemi continua sob investigação nos dias de hoje por procuradores do Ministério Público Federal. Ver portal "Amazônia: notícia e informação". Endereço: <http://amazonia.org.br/2014/04/mpf-investigaprejuizos-provocados-por-empresa-vinculada-a-militares-em-obras-da-hidreletrica-de-tucurui/>. Acesso em: 14 de fevereiro de 2018.
} 
participação da empresa brasileira foi vendida e hoje a fábrica está sob o controle da norueguesa Norsk Hydro. A fábrica Alunorte também ficava na grande Belém e tinha 39,2\% de participação de capital japonês e $60 \%$ da Vale, contando com investimentos de US\$ 580 milhões. Havia também a Alumar, fábrica de grande porte situada em São Luís do Maranhão, com capital da norte-americana Alcoa, da Billington Metais (subsidiária da Shell) e da Camargo Corrêa, com investimentos previstos de US\$ 1 bilhão no início dos anos 1980. Havia ainda um projeto de menor porte, situado em Recife, com participação de capital alemão. Essas fábricas fizeram quadruplicar a produção nacional de alumínio (O EMPREITEIRO, 1981).

A eletricidade gerada por Tucuruí seria em boa medida consumida por essas grandes fábricas de alumínio, de padrão eletrointensivo. Essas indústrias foram inauguradas em meados dos anos 1980. Assim, em sua capacidade máxima, a previsão era que o complexo Albrás-Alunorte consumisse $600 \mathrm{MW}$ e a planta da Alumar, $620 \mathrm{MW}$. Uma polêmica em torno dessas fábricas e do fornecimento de energia diz respeito ao fato de que eram projetos dedicados, sobretudo, à exportação, vendendo para o mercado internacional um item que tinha em boa medida a energia como componente do seu valor. Assim, tratava-se da exportação de um semimanufaturado, sem grande agregação de valor (O EMPREITEIRO, 1984).

Inicialmente, os empresários japoneses entraram como sócios também da própria empresa estatal de eletricidade. Assim, com a chamada Lei Dias Leite, promulgada pelo ditador Emílio Garrastazu Médici em 10 de dezembro de 1973, era permitida a participação de empresas industriais na composição acionária de firmas concessionárias de energia elétrica da região amazônica. Isso permitia que as companhias japonesas pudessem fazer parte da composição do capital da Eletronorte (CENTRAIS ELÉTRICAS DO NORTE DO BRASIL S/A, 2004; PINTO, 2010), o que, conforme veremos adiante, acabou não ocorrendo.

Porém, o aspecto mais questionado diz respeito aos subsídios determinados ao fornecimento de energia por parte de Tucuruí a essas fábricas. Pelos contratos assinados com as empresas japonesas pela Eletronorte, a energia fornecida às fábricas no Pará teria um preço cativo durante 20 anos, entre 1984 e 2004, com 15\% de redução em relação ao 
preço do mercado. Isso garantia uma energia a um preço extremamente módico para as fábricas com alta participação de capital estrangeiro. O deputado Horácio Ortiz (MDB-SP) acreditava que as isenções e os acordos eram "altamente lesivos aos interesses nacionais" (ORTIZ, 1980, p. 9) e o professor da UFPA, Ruy Raymundo Bahia, calculou que os subsídios na energia elétrica fornecida às fábricas somaram um total de US\$ 5 bilhões de renúncia fiscal nos seus 20 anos de vigência. Em 2004, o governo Lula resolveu prorrogar por mais 20 anos os subsídios na energia elétrica fornecida pela Eletronorte às fábricas de alumínio no Pará (PINTO, 2010).

Além disso, ao longo do projeto, com o sucessivo redimensionamento do mesmo tanto da usina de Tucuruí, como das fábricas de alumínio - e a elevação dos gastos com juros, os japoneses foram retirando sua participação das obras da hidrelétrica e das fábricas e esses custos foram absorvidos pelo governo brasileiro. O deputado Horácio Ortiz afirmou que o Brasil estava sustentando a prosperidade japonesa e o empresário Eliezer Batista acusou corrupção na obra da usina, relacionada aos subsídios de energia elétrica às fábricas de alumínio (ORTIZ, 1980; PINTO, 2010).

Para além dos interesses empresariais japoneses, presentes na exploração e beneficiamento da bauxita e no consumo da energia subsidiada de Tucuruí, o empreendimento teve outros grupos capitalistas envolvidos, particularmente no seu financiamento e fornecimento de equipamentos para a usina. Assim, diversos bancos fizeram empréstimos para a construção da usina e empresas industriais forneceram turbinas e geradores para a hidrelétrica, em particular bancos e indústrias francesas.

A usina hidrelétrica de Tucuruí recebeu para a sua obra um tipo particular de empréstimo intitulado supplier crédit, no qual grupos financiam um projeto com a condição de que parte desses recursos seja usada para a compra de equipamentos específicos junto a certas empresas. Assim, a Eletronorte teve o empréstimo de um pool de bancos franceses liderados pelo L'Union Européenne, que financiaram US\$ 260 milhões para a compra dos equipamentos que funcionariam na usina, produzidos pela empresa francesa Creusot-Loire. Foram 23 turbinas, 12 na primeira fase da usina e mais 11 na segunda etapa. Dessas 12 iniciais, metade foi feita na França e a outra metade no Brasil, com pagamento de royalties à matriz francesa. O índice de nacionalização da construção 
de equipamentos foi da ordem de 60\%, o que alguns críticos consideraram baixo (CENTRAIS ELÉTRICAS DO NORTE DO BRASIL S/A, 2004; MELLO, 2009; ROSA et al., 1988).

A negociação foi tocada no lado brasileiro pelo presidente da Eletrobrás, Antonio Carlos Magalhães. Em sua memória, Henrique Mello, engenheiro da Eletronorte envolvido no processo, defende a ideia de que a postura da delegação brasileira fez com que fosse feita uma economia na compra dos equipamentos, que ele cogita, da ordem de US\$100 milhões (Mello, 2009). Antes, o embaixador brasileiro da França, Antonio Delfim Netto, esteve envolvido na intermediação entre os empresários franceses com o governo brasileiro. Delfim encarou denúncias de cobrança de propina junto aos banqueiros franceses para a compra e financiamento dos equipamentos de Tucuruí e também na usina hidrelétrica de Água Vermelha, da Cesp (Companhia Energética do Estado de São Paulo), no que ficou conhecido como o relatório Saraiva (GASPARI, 2003; GRAEL, 1985).

Ao final, foram contratados US\$ 560 milhões junto a bancos estrangeiros, além de empréstimos tomados junto ao Banco do Brasil, Caixa Econômica Federal, Banco Nacional de Habitação (BNH), Finame, Banco Nacional de Desenvolvimento Econômico (BNDE) e Eletrobrás, no valor de US\$ 1,455 bilhão. Os custos com o financiamento foram se elevando ao longo da obra, com o seu retardamento e com a elevação dos juros praticados no mercado internacional (CENTRAIS ELÉTRICAS DO NORTE DO BRASIL S/A, 1989).

Assim, os interesses estrangeiros relacionados à obra de Tucuruí estiveram relacionados à exploração, beneficiamento e exportação do alumínio, além do financiamento e fornecimento de equipamentos para a obra. Conforme verificamos - e isso parece ser mais um elemento que expressa uma característica bastante notável da ditadura brasileira - a hidrelétrica representou a implantação de um projeto parcialmente primário-exportador, com alta dependência tecnológica externa, que gerou uma elevada dívida pública - em particular externa - e trouxe benefícios bastante acentuados às empresas envolvidas no empreendimento com seus subsídios e facilitações, em particular algumas estrangeiras. 


\section{Interesses domésticos em torno do projeto de Tucuruí}

Os empreiteiros de obras públicas constituíram alguns dos principais empresários que apoiaram o golpe de Estado de 1964 e conferiram apoio ao regime ditatorial. Donos de empresas com capital majoritariamente brasileiro, esses empresários estavam organizados no Sindicato Nacional de Construção Pesada (Sinicon) e contribuíram com o Ipes e com o movimento de derrubada da democracia. Em contrapartida, foram amplamente beneficiados pelas políticas implementadas ao longo da ditadura, sendo favorecidos com reserva de mercado, financiamento facilitado, isenções fiscais e direcionamento do fundo público para suas atividades (CAMPOS, 2014). Tudo isso está expresso na obra de Tucuruí.

Uma única construtora foi responsável por todas as obras civis da usina. A paulista Camargo Corrêa, de propriedade de Sebastião Camargo, foi a maior de todas as empreiteiras brasileiras durante a ditadura. Era a maior barrageira do país, tendo em seu portfólio boa parte da capacidade instalada do estado de São Paulo, além de ter participado, junto com outras, da obra da usina de Itaipu, a maior do mundo naquele momento. Além disso, desde o final da década de 1970, tinha atividades no exterior, onde era a responsável pela construção da hidrelétrica de Guri, na Venezuela, a segunda maior do mundo até então. A Caterpillar - principal fabricante de máquinas usadas na construção civil do mundo - fez um estudo no início da década de 1980 e verificou que a Camargo Corrêa era, naquele momento, a construtora que mais possuía equipamentos seus de todo o planeta. Dessa forma, pode-se deduzir que a Camargo Corrêa possivelmente chegou a ser, em certa situação, a maior empreiteira do globo, ao menos levando em conta a quantidade de equipamentos Caterpillar que operava na época (CAMPOS, 2014). Seu dono, Sebastião Camargo, foi o primeiro brasileiro a figurar como bilionário nas listas da Forbes e da Fortune, já na década de 1980 (PINTO, 2010).

A mesma empreiteira que cresceu muito durante a ditadura e era próxima de vários agentes do regime, como o ministro Delfim Neto e outros, era também uma empresa conhecida por seu histórico de truculência. No seu currículo constam várias reclamações de maus tratos em relação aos trabalhadores e acusações de irregularidades e pagamentos de propina a agentes públicos. Além disso, a Camargo Corrêa é conhecida 
por ser uma das empresas que contribuiu com a Operação Bandeirantes, responsável pela perseguição, prisão, tortura e assassinato dos integrantes da resistência armada à ditadura (BANDEIRA, 1975; GASPARI, 2002; CAMPOS, 2014).

Essa mesma empresa esteve relacionada a uma série de polêmicas e situações delicadas envolvendo a construção da hidrelétrica de Tucuruí. No caso, elas tiveram início já no período de concorrência para a realização da obra. Os lances das empresas na licitação foram os seguintes:

Tabela 1 - Resultado da licitação das obras civis da usina hidrelétrica de Tucuruí em 1976:

\begin{tabular}{|l|c|}
\hline Empresa: & Lance (em Cr\$): \\
\hline Camargo Corrêa & 7,6 bilhões \\
\hline Mendes Júnior & 9,3 bilhões \\
\hline Andrade Gutierrez & 11,9 bilhões \\
\hline CR Almeida & 14,9 bilhões \\
\hline
\end{tabular}

Fonte: CENTRAIS , 1989, p. 368.

Três outras empresas se apresentaram para participar da obra: a Rabello, a Cetenco e a CBPO. A primeira foi desclassificada e as outras duas não apresentaram propostas. Com isso, a Camargo Corrêa, ao apresentar o menor preço para realizar a obra, foi considerada a vencedora e ficou responsável pelo empreendimento.

No entanto, as concorrências havidas durante aquele período não gozavam de muita credibilidade. Dessa forma, o pequeno empreiteiro Haroldo Guanabara assim se referiu aos chamados "editais sujos":

No setor de obras, uma prática que deforma as disputas é a chamada 'concorrência dirigida'. É comum entre os empreiteiros, assim que um edital é publicado, ocorrer a pergunta: Quem é o dono desta? Trata-se da vitória do lobby e não da competência. Este fato, no Brasil dos últimos anos, é tão verdadeiro, que levou a uma enorme concentração de obras nas mãos de somente quatro macroempresas. São as que detêm o mais eficiente lobby. (GUANABARA apud ASSOCIAÇÃO DA EMPRESAS DE ENGENHARIA DO RIO DE JANEIRO, 2005, p. 142) 
Assim, as concorrências no período eram conhecidas como "meros atos formais", como indicado pela revista O Empreiteiro ${ }^{6}$ (O EMPREITEIRO, 1977, p. 3). A mesma revista indica como na época era amplamente conhecido o resultado de uma concorrência por quem era do meio antes da sua realização e que isso favorecia as grandes empresas, em detrimento das pequenas e médias (O EMPREITEIRO, 1977).

Sobre essa mesma questão, é reveladora a fala do então chefe do Serviço Nacional de Informações (SNI), general João Batista Figueiredo, ao também general Golbery do Couto e Silva em 1973, conforme registrado no livro de Elio Gaspari:

Eu tive uma documentação que eu levei para o presidente há uns meses atrás, do Delfim, de que antes da concorrência, aquela da Água Vermelha, ele afirmava a um grupo francês que queria entrar no financiamento, de que a firma construtora seria a Camargo Corrêa. Antes da concorrência. Então está aí, na cara. É Camargo Corrêa, é Bradesco, é tudo a mesma panela. (GASPARI, 2003, p. 273)

O então chefe da espionagem brasileira revela que grampeava o ministro da Fazenda e que o monitorava fazendo intermediações de negócios entre empresários brasileiros e financiadores no exterior. Indica ainda que Delfim sabia antes da licitação qual empresa venceria o pleito.

As irregularidades envolvendo empreiteiras e concorrências públicas no período não se esgotam aí. Havia toda uma prática no sentido de obter facilidades no período posterior à concorrência. O depoimento de um empreiteiro anônimo, gravado pelo economista Galeno Tinoco Ferraz Filho, parece ajudar a esclarecer como se procede isso:

Existem duas posições fundamentais e regras básicas. O bom empreiteiro é aquele que faz duas coisas: primeiro, cria a obra. Você criando a obra, ela é sua ao nascer; a concorrência é outro papo. E funciona em $90 \%$ dos casos. Isso é a primeira regra. A segunda regra, é a seguinte - essa já é numa fase posterior - bom empreiteiro é aquele que a transforma num bom negócio. Porque contrato de obra, qualquer um tem. Fazer desse

\footnotetext{
${ }^{6}$ A revista $O$ Empreiteiro começou a ser publicada na forma de periódico ilustrado mensal a partir de fevereiro de 1968 e remonta a um boletim de classificados de máquinas para a construção que circulava desde o início dos anos 60. Trata-se da mais importante revista sobre o setor da construção pesada no país, editada até os dias atuais. Era dirigida no período da ditadura por Joseph Young, que atuou antes na Caterpillar. Seu conselho consultivo era formado por engenheiros ligados a empreiteiras e os principais anunciantes eram fabricantes de máquinas e equipamentos para obras de infraestrutura. Sobre a revista, ver: Campos, 2016.
} 
contrato um bom negócio, esse é o bom empreiteiro. Porque não tem nenhum contrato que termine como começou. Não tem um. [...]

A CR Almeida entrou, numa determinada concorrência, com um preço da ordem de sete bilhões. A Mendes entrou com sete bilhões e meio, a Cetenco entrou com sete bilhões. A Camargo ganhou a concorrência com quatro bilhões. A preços iniciais da obra, porque você para ter uma referência utiliza os preços iniciais. O contrato inicial da Camargo era quatro bilhões. Entretanto, entre outras coisas a Camargo conseguiu botar lá dentro uma eclusa de trezentos milhões de dólares. Essa foi aquela segunda etapa que eu falei. Do transformar um contrato em um bom negócio. $O$ contrato ele pegou por um preço que o levaria à falência. Não dava para perder três bilhões de cruzeiros. Depois então que já pegara esse contrato, mudou e incluiu a eclusa. (FERRAZ FILHO, 1981, p. 104-105)

O empresário entrevistado dá a entender que muitas vezes os empreiteiros elaboram os projetos das obras que são depois abraçadas enquanto projetos estatais. Além disso, indica que os empreiteiros ao longo da obra usam de diversos mecanismos para transformar o empreendimento em um negócio lucrativo, geralmente a partir de aditivos ao contrato original.

A Camargo Corrêa particularmente era conhecida por modificar a obra para tornála mais rentável. O alto funcionário da empresa assim se refere a essa reputação da companhia: "A Camargo Corrêa tinha a fama de sempre apresentar uma conta nova no curso das obras, como maneira de ganhar mais dinheiro. Estávamos, porém, em busca de melhores soluções" (QUINTELLA, 2008, p. 22).

O caso de Tucuruí parece ser representativo dessa tendência. Segundo denúncia da revista Veja, publicada em abril de 2001, a obra teve um total de 29 aditivos, esticando os serviços e multiplicando o valor inicial do contrato. Obras auxiliares, como a construção das eclusas e a duplicação de Tucuruí, também ficaram a cargo da Camargo Corrêa (PINTO, 2010).

De acordo com a memória de Wilson Quintella, esses sucessivos pedidos de adições ao contrato geraram algumas dificuldades para a empreiteira junto à Eletronorte. A empresa usou diversas brechas no edital para aumentar o valor da obra. Funcionários da Eletronorte chegaram a cogitar o cancelamento do contrato e a assinatura de um novo com a segunda colocada na licitação. Em certa ocasião ao longo da obra, a Camargo 
Corrêa queria mudar um item do edital que dizia respeito ao cimento utilizado na barragem. Previa-se inicialmente o uso de cimento de conchas da Colômbia e a Camargo Corrêa considerava o seu uso arriscado. Quintella relata um diálogo tenso havido entre os técnicos da empresa e os da estatal, na qual um engenheiro da mesma teria dito o seguinte: “A proposta da Mendes Júnior adota esse cimento de conchas, cujo preço é muito mais barato que o Portland proposto por vocês, e a Eletronorte está disposta a correr esse risco" (QUINTELLA, 2008, p. 385). Quintella relata ter argumentado em favor da segurança do tipo de cimento pleiteado pela construtora, no que o funcionário da Eletronorte teria retrucado: "Sei como uma empreiteira age, e nessa altura vocês já devem ter comprado até o contínuo da Eletronorte para lhes dar uma cópia das propostas concorrentes" (QUINTELLA, 2008, p. 385). O relato é certamente parcial e seletivo, mas dá um indicativo das tensões havidas ao longo da obra e dos mecanismos usados pela empresa para ampliar seus ganhos com o projeto.

No entanto, os favorecimentos para a Camargo Corrêa não se esgotaram nos aditivos ao contrato. Por decreto do ditador Ernesto Geisel, a construtora foi isenta de pagar o Imposto Sobre Serviços (ISS) na obra, penalizando o município, que receberia o tributo recolhido pela empresa e poderia utilizá-lo para minorar os efeitos danosos do projeto de grande porte (PINTO, 2010). Além disso, a empreiteira ganhou outra renúncia fiscal, no seu Imposto de Renda. Por outra ação do governo, a Camargo Corrêa foi isentada de colher o imposto caso revertesse o que seria arrecadado em iniciativas relacionadas ao projeto Grande Carajás. Assim, a construtora paulista investiu US\$235 milhões ingressando como sócia de multinacionais na fábrica Alumar, em São Luís. Desses recursos investidos pela companhia, $20 \%$ eram próprios e $80 \%$ eram oriundos das isenções fiscais do IRPJ. Com isso, a Camargo Corrêa se tornou sócia da Alluminium Company of America (Alcoa), detendo $37 \%$ do capital da Alcoa Alumínio no Brasil (SINDICATO NACIONAL DA CONSTRUÇÃO PESADA, 1984). Assim, percebemos como há uma associação entre os interesses estrangeiros com os de capital dominante doméstico em torno de projetos como o de Tucuruí e outros havidos durante a ditadura.

Dessa maneira, o projeto permitiu o crescimento da fortuna de Sebastião Camargo e o fortalecimento e ramificação da empresa, que era uma das maiores do país na década 
de 1980. Todo esse favorecimento, bem como o caráter extremamente audacioso do projeto, levaram a vários questionamentos. No compasso do processo de abertura e transição política, essas críticas vinham à tona de maneira cada vez mais explícita e intensa. Na Câmara dos Deputados, o parlamentar e ex-empreiteiro paulista Horácio Ortiz, do MDB de São Paulo, fez o seguinte pronunciamento na sessão de 29 de novembro de 1979:

Foi esse, exatamente, Sr. Presidente, um dos aspectos mais controvertidos quando do planejamento dessa usina. Embora reconheçamos a necessidade de implantação de um sistema hidrelétrico atendendo à Região Amazônica, é o nosso entendimento - e de um grande número de técnicos - que instalações hidrelétricas de porte médio permitiriam fazer o abastecimento hidrelétrico de uma forma precisa, quase imediata, e a custo 10 a 20 vezes menor. Sabemos, por exemplo, que Manaus se situa a cerca de 800 quilômetros dessa usina. Somente a linha de transmissão custará quase um bilhão de dólares, quantia que praticamente seria suficiente para construir uma hidrelétrica de porte médio, de talvez 200 mil quilowatts. (ORTIZ, 1980, p. 6, grifo nosso)

O deputado chamava a atenção para alternativas ao projeto da usina que ele chamava de faraônico. Era possível fazer hidrelétricas menores a um custo mais módico. Mesmo defendendo a geração de energia elétrica pela via hidráulica, o engenheiro atentava para a falta de necessidade de usinas do porte de Tucuruí, alertando também para os seus impactos sócio-ambientais. No entanto, no mesmo discurso, ele indicou suas suspeitas sobre o porquê do projeto do porte de Tucuruí ter sido implementado:

O que não posso aceitar pacificamente, agachado e mudo, Sr. Presidente, é a insânia e o destempero da opção pela construção de uma monstruosa hidrelétrica cuja oportunidade e conveniência era e continua sendo contestada pelas luzes cristalinas da realidade. A obstinação com que o Governo se empenhou no projeto, mesmo ciente das várias condicionantes que o desaconselhavam, leva-me a vislumbrar objetivos nada ingênuos na sua realização a todo custo, vinculados a interesses não-nacionais, assaz visíveis neste e em tantos outros empreendimentos em curso no País, e dos grandes grupos econômicos que constroem barragens, represas e outras obras deste jaez. (ORTIZ, 1980, p. 15, grifo nosso)

Com o depoimento, Ortiz indicava que havia os interessados pelo projeto com aquele tamanho. São justamente as grandes empreiteiras, os consumidores de energia eletro-intensiva e os fabricantes de equipamentos elétricos de grande porte que ganhavam com uma obra daquela monta. 
Verificamos nesse trecho como as empresas brasileiras de engenharia foram beneficiadas pela implementação de Tucuruí, com destaque para o caso da empreiteira Camargo Corrêa. Através de aditivos ao contrato, isenções fiscais e dotações orçamentárias, a empresa se apropriava do fundo público para crescer e conglomerar, tornando-a um complexo empresarial presente em diversos segmentos da economia e com braços no exterior.

Porém, para além desses mecanismos de favorecimento do empresariado envolvido no projeto, há uma última forma de beneficiamento que precisamos tratar antes de concluir o artigo. Trata-se da política da ditadura em relação à classe trabalhadora. Através dela, as diferentes empresas envolvidas em Tucuruí, e outros projetos do período, foram beneficiados indiretamente, por terem uma força de trabalho mais barata e teoricamente obediente e passiva. No entanto, nem tudo ocorreu como planejado pela ditadura e pelos empresários.

\section{Repressão aos trabalhadores e favorecimento dos empresários em Tucuruí}

A ditadura foi responsável por uma política altamente agressiva e violenta contra a classe trabalhadora brasileira. Logo após o golpe de Estado, houve a intervenção em quatro das seis centrais sindicais, destituição da diretoria de 563 sindicatos, proibição da greve na maior parte dos casos, através da Lei Anti-Greve, e foram liberados os preços de produtos fundamentais, fazendo com que se elevasse o custo de vida, algo sentido principalmente pela classe trabalhadora e pelos estratos mais pobres da população. Nos dez primeiros anos da ditadura, o salário mínimo - índice geral dos proventos na economia brasileira - teve elevação inferior à inflação, o que fez com que ele perdesse $41 \%$ do seu poder de compra nesse período. Houve elevação na proporção de trabalho feminino e infantil e a ditadura pouco fiscalizava os itens de segurança do trabalho. Isso fez com que se elevassem de maneira muita intensa os acidentes de trabalho, muitos deles fatais. Na década de 1970, o Brasil se tornou recordista internacional de acidentes de trabalho e o setor da construção civil era o líder dessa estatística, inclusive em mortes (CAMPOS, 2014). 
Essas políticas incorriam em favorecimento aos empresários, que tinham menor custo com a força de trabalho e também acabavam lidando com trabalhadores menos combativos, tendo em vista a intensa repressão sobre os sindicatos e suas lideranças. Isso era especialmente proveitoso para as empreiteiras e os grandes projetos tocados pelo regime, que absorviam uma numerosa força de trabalho, conforme ocorreu nas obras de Tucuruí e nos projetos associados à mesma, como as usinas de alumínio do Pará e do Maranhão.

Dessa forma, Tucuruí também expressa essa face obscura da ditadura. Trabalharam na construção da usina dezenas de milhares de operários. No pique das obras, a quantidade de trabalhadores que atuavam no empreendimento era de 30.200 operários. Assim, segundo os dados oficiais presentes na memória técnica da construção da usina, o número de acidentes de trabalho foi bastante elevado ao longo das obras. Somente no que diz respeito aos óbitos, foram um total de 97 operários mortos na construção da usina, entre 1979 e 1986 (CENTRAIS ELÉTRICAS DO NORTE DO BRASIL S/A, 1989, p. 395), um número extremamente elevado.

No entanto, apesar desses dados, que mostram um quadro grave no canteiro de obras, o diretor da Camargo Corrêa afirma o seguinte em sua memória: "Na organização dos acampamentos de trabalho, proporcionávamos vida de Primeiro Mundo ao nosso pessoal. [...] Essa foi uma das razões pelas quais nunca enfrentamos tumultos em nossos canteiros" (QUINTELLA, 2008, p. 21, grifo nosso). Apesar do relato idílico sobre a vida no canteiro de obras, isso não foi o que se verificou no canteiro de obras da usina de Tucuruí. Em abril de 1980, houve ali a maior rebelião da história brasileira até então ocorrida em uma obra de usina hidrelétrica, conforme relato da revista O Empreiteiro:

Motim no canteiro - os operários se revoltam [...]

A revolta começou com uma brincadeira dos peões: a malhação de um judas que representava um dos vigilantes da Camargo Corrêa. Vigilantes fortemente armados confiscaram o judas e prenderam os peões que comandavam a brincadeira. (O EMPREITEIRO, 1980A, p. 7)

A rebelião estourou no sábado de Aleluia. Os trabalhadores revoltados quebraram dois refeitórios, saquearam o supermercado que servia à vila dos operários e atearam fogo contra o centro de vigilância. A polícia militar paraense foi ao local e interveio com 
violência, ferindo à bala alguns operários. Os trabalhadores entraram em greve e exigiram aumento salarial de 100\%, além de melhorias nos alojamentos, transportes e alimentação (O EMPREITEIRO, 1980A).

A situação foi bastante tensa e ocorria em meio a um contexto de greves ao longo do país e revigoramento do sindicalismo e movimento de trabalhadores. Na ocasião, foi feito um acordo, com atendimento de parte das reivindicações operárias e a obra foi continuada.

Assim, a política endereçada aos trabalhadores era benéfica para os empresários durante a ditadura, porém a repressão e violência tinham um limite. Os operários se revoltaram na obra de Tucuruí, expressando seu descontentamento e revolta diante da forma como eram tratados no canteiro, remunerados e reprimidos nas suas ações em momentos de lazer e descanso.

\section{Conclusão}

Tucuruí só saiu - e como saiu - porque foi toda construída sob um regime de exceção, sustentado pelas Forças Armadas, em especial o Exército. (PINTO, 2010, p. 10)

O projeto da usina hidrelétrica de Tucuruí tem muito a revelar acerca da ditadura brasileira. De fato, entendemos que temos ali um microcosmo do regime, em diversas feições e dimensões do seu caráter autoritário e de sua própria composição social. Para além da falta de democracia na forma como o projeto foi elaborado e conduzido, sem consulta às comunidades locais, ignorando os impactos sociais decorrentes da megausina e de seu reservatório, além de todos os danos ambientais causados pela barragem, a obra é reveladora da ditadura na medida em que ela expressa interesses empresariais que constituíram os seus beneficiários. A falta de transparência no uso dos recursos públicos e que se expressava na forma obscura como foi elaborado o projeto, o edital da obra, o contrato e seus aditivos serviu para favorecer certos interesses empresariais que atuaram no projeto. Assim, todo o sacrifício das milhares de famílias trabalhadoras afetadas serviu para favorecer e enriquecer certos grandes interesses econômicos privados. 
De porte da ferramenta metodológica do Estado ampliado, é possível verificar e analisar os diferentes interesses envolvidos no projeto e mesmo responsáveis pela sua concepção e desenrolar ao longo da obra, em particular o capital monopolista estrangeiro e doméstico, com seus projetos e integrantes inseridos junto às agências estatais no período. Na obra, militares puderam atuar como sócios do empreendimento ao poderem explorar madeira da região inundada. Esse projeto de desmatamento não foi plenamente concluído, mas a concessão à Capemi estava prevista na sua implementação. Multinacionais estrangeiras se beneficiaram das isenções fiscais, prioridade dada ao projeto por parte do governo brasileiro e da grandiloquência do mesmo, que gerava energia elétrica a baixo custo e subsidiada para produzir alumínio e outros produtos a um valor menor e com possibilidades de elevadas margens de ganho, tendo em vista as facilidades previstas na sua fabricação. Foram beneficiadas também empresas brasileiras, como o caso notório da empreiteira Camargo Corrêa, favorecida por um contrato que teve seguidos aditivos, isenções fiscais e recursos de monta, que fizeram a empresa se apropriar de forma significativa do fundo público do Estado brasileiro. Por fim, a própria política endereçada aos trabalhadores gerava benefícios para os empresários envolvidos, tendo em vista que proporcionava uma força de trabalho barata e que tendia a ser mais passiva diante dos patrões, dado o caráter autoritário do regime. Além disso, conforme vimos, a obra gerou endividamento público, dependência externa e concentração de renda.

Dessa forma, entendemos que Tucuruí traz diversos elementos que caracterizam a própria ditadura em seu perfil de classe, conforme apontado por Dreifuss (1981). Como se vê, os beneficiários da obra expressam não só agentes que se favoreceram de suas políticas e medidas. Esses empreiteiros, empresários estrangeiros e capital multinacional, na perspectiva do Estado ampliado, constituíam a própria ditadura. O projeto de modernização capitalista acelerada e autoritária implementado pelo regime tinha como agentes e beneficiários diretos esses interesses que estavam presentes em iniciativas como a de Tucuruí e de outros projetos tocados pela ditadura empresarial-militar brasileira. 


\section{Referências}

ACSELRAD, Henri. Planejamento autoritário e desordem socioambiental na Amazônia: crônica do deslocamento das populações de Tucuruí. Revista de Administração Pública, v. 25 , n. 4 , p. 53-68, 1991.

ASSIS, José Carlos de. Os sete mandamentos do jornalismo investigativo: inteligência, ética e coragem na construção da reportagem. Rio de Janeiro: Textonovo, 2015.

ASSOCIAÇÃO DA EMPRESAS DE ENGENHARIA DO RIO DE JANEIRO. AEERJ 30 Anos: 30 anos de obras públicas no Rio de Janeiro (1975-2005). Rio de Janeiro: AEERJ, 2005.

BANDEIRA, Luiz Alberto Moniz. Cartéis e desnacionalização: a experiência brasileira, 1964-1974. Rio de Janeiro: Civilização Brasileira, 1975.

BATISTA, Eliezer. Depoimento. In: ELIEZER Batista: o engenheiro do Brasil. Direção de Victor Lopes. [S. I.: s.n.], 2009. 1 vídeo (84 min.). Disponível em:

https://www.youtube.com/watch?v=kgT2CmB17Dc. Acesso em: 12 de jan. de 2018.

CAMPOS, Pedro Henrique Pedreira. Estranhas catedrais: as empreiteiras brasileiras e a ditadura civil-militar, 1964-1988. Niterói: Eduff, 2014.

CAMPOS, Pedro Henrique Pedreira. Periódicos técnicos e apoio a ditadura civil-militar brasileira: o caso da revista O Empreiteiro, 1964-1988. In: CORRÊA, Maria Letícia; CHAVES, Monica Piccolo Almeida; BRANDÃO, Rafael Vaz da Motta (Org.). História econômica e imprensa. Rio de Janeiro: Contracapa, 2016, p. 177-196.

CAPEMI história 1977. [S. I.: s. n.], 2016. (1 vídeo) 36 min. Publicado pelo canal Lar Fabiano de Cristo. Disponível em: https://www.youtube.com/ watch?v=rFRiGqDXU5c\&feature=youtu.be. Acesso em: 11 jan. 2018.

CASTRO, Antonio Barros de; SOUZA, Francisco Eduardo Pires de. A economia brasileira em marcha forçada. 2. ed. Rio de Janeiro: Paz e Terra, 1985.

D’ARAÚJO, Maria Celina; CASTRO, Celso (Org.). Ernesto Geisel. 4. ed. Rio de Janeiro: EdFGV, 1997.

DREIFUSS, René Armand. 1964: a conquista do Estado. 3. ed. Petrópolis: Vozes, 1981.

CENTRAIS ELÉTRICAS DO NORTE DO BRASIL S/A. Eletronorte: 30 anos de pura energia. Rio de Janeiro: Centro de Memória da Eletricidade, 2004.

CENTRAIS ELÉTRICAS DO NORTE DO BRASIL S/A. Memória Técnica: usina hidrelétrica de Tucuruí. Brasília: Projeto Memória Eletronorte, 1989. 
FERRAZ FILHO, Galeno Tinoco. A transnacionalização da grande engenharia brasileira. 1981. Dissertação (Mestrado em Economia) - Unicamp, São Paulo, 1981.

FONSECA, Pedro Cezar Dutra; MONTEIRO, Sergio Marley Modesto. O Estado e as suas razões: o II PND. Revista de Economia Política, v. 28, n. 109, p. 28-29, 2007.

GASPARI, Elio. A ditadura derrotada. São Paulo: Companhia das Letras, 2003

GASPARI, Elio. A ditadura escancarada. São Paulo: Companhia das Letras, 2002.

GRAEL, Dickson M. Aventura, terrorismo e corrupção: à sombra da impunidade. Petrópolis: Vozes, 1985.

GRAMSCI, Antonio. Cadernos do cárcere. volume 3: Maquiavel; notas sobre o Estado e a política. Rio de Janeiro: Civilização Brasileira, 2000.

LESSA, Carlos. Estratégia de desenvolvimento 1974-1976: sonho e fracasso. Brasília: Funcep, 1988

MELLO, Henrique. A engenharia como missão. Rio de Janeiro: Centro de Memória da Eletricidade, 2009.

MANTEGA, Guido; MORAES, Maria. Acumulação Monopolista e Crises no Brasil. Rio de Janeiro: Paz e Terra, 1980.

MENDONÇA, Sonia Regina de. Estado e economia no Brasil: opções de desenvolvimento. Rio de Janeiro: Graal, 1985.

MENDONÇA, Sonia Regina de. Estado e educação rural no Brasil: alguns escritos. Rio de Janeiro: Faperj, 2007.

OLIVEIRA, Ariovaldo Umbelino de. Integrar para não entregar: políticas públicas e Amazônia. Campinas: Papirus, 1991.

OLIVEIRA, Francisco de. Crítica à razão dualista. In: OLIVEIRA, Francisco de. A crítica da razão dualista: o ornitorrinco. São Paulo: Boitempo, 2003.

OLIVEIRA, Francisco de. Padrões de acumulação, oligopólios e Estado no Brasil, 19501976. In: A economia da dependência imperfeita. 2. ed. Rio de Janeiro: Graal, 1977, p. 76113.

ORTIZ, Horácio. Tucuruí: contradições de uma obra faraônica. In: ANAIS da Câmara dos Deputados. Brasília: Câmara dos Deputados, 1980. 
PINTO, Lúcio Flávio. Tucuruí: a barragem da ditadura. Belém: Edição do autor, 2010

PRADO, Luiz Carlos Delorme; EARP, Fábio Sá. O “milagre” brasileiro: crescimento acelerado, integração internacional e concentração de renda (1967-1973)". In: FERREIRA, Jorge; DELGADO, Lucília de Almeida (Org.). O Brasil republicano: vol. 4: o tempo da ditadura: regime militar e movimentos sociais em fins do século XX. Rio de Janeiro: Civilização Brasileira, 2003, p. 209-241.

QUINTELLA, Wilson. Memórias do Brasil Grande: a história das maiores obras do país dos homens que as fizeram. São Paulo: Saraiva, 2008.

EDITORIAL. Revista O Empreiteiro. São Paulo, n. 115, agosto 1977, p. 3.

MOTIM no canteiro. Revista O Empreiteiro, São Paulo, n. 148, maio 1980a, p. 7-12.

CARAJÁS / ferrovias. Revista O Empreiteiro, São Paulo, n. 149, jun. 1980a, p. 50-53.

20 ANOS - as condições para voltar a crescer. Revista O Empreiteiro,São Paulo, n. 165, set. 1981, p. 30-54.

CONSTRUÇÃO - Tucuruí antecipa geração. Revista O Empreiteiro. São Paulo, n. 204, nov. 1984, p. 5 .

ROSA, Luiz Pinguelli; SIGAUD, Lygia; MIELNIK, Otavio (Org.). Impactos dos grandes projetos hidrelétricos e nucleares: aspectos econômicos, tecnológicos, ambientais e sociais. São Paulo: Marco Zero, 1988.

SILVA, Francisco Carlos Teixeira da. A modernização autoritária: do golpe militar à redemocratização, 1964-1984. In: Maria Yedda Leite Linhares (Org.). História geral do Brasil. 9. ed. atual. Rio de Janeiro: Campus, 2000, p. 351-384.

SINGER, Paul. A Crise do “Milagre”: interpretação crítica da economia brasileira. 4. ed. Rio de Janeiro: Paz e Terra, 1978.

SINDICATO NACIONAL DA CONSTRUÇÃO PESADA. Informe Sinicon. Rio de Janeiro, n· 18, ano I, jun. 1984. 
Recebido em 11/08/2018 Aprovado em 18/03/2019

Universidade do Estado de Santa Catarina - UDESC Programa de Pós-Graduação em História - PPGH Revista Tempo e Argumento Volume 11 - Número 26 - Ano 2019 tempoeargumento@gmail.com 